\title{
Epidemiological Studies of Diabetes Mellitus in Denmark: 3. Clinical Characteristics and Incidence of Diabetes Among Males Aged 0 to 19 Years
}

\author{
A. Green ${ }^{1}$ and P.K. Andersen ${ }^{2}$ \\ ${ }^{1}$ University Institute of Clinical Genetics, Odense, and ${ }^{2}$ Statistical Research Unit, Danish Medical and Social Science Research Councils, \\ Copenhagen, Denmark
}

Summary. This study presents the clinical-epidemiological analysis of data from 769 individuals, representing $>95 \%$ of all cases of diabetes mellitus diagnosed during the first 20 years of life among the Danish male birth cohorts 1949-1956 inclusive. It is concluded that except for a very few, all cases of diabetes developing during the first 20 years of life are insulindependent with a duration of symptoms $<2$ months before diagnosis in $>75 \%$ of the cases. The cases were evenly distributed within Denmark at the time of birth as well as of diagnosis, and $>98 \%$ were admitted to hospital at diagnosis. A relatively higher proportion of cases diagnosed during autumn and winter periods was found, but was not statistically significant. Incidence was analysed in a regression model with age and calendar time as variables; the variation of age at onset was similar to previous studies with a peak at pre-school age and at puberty. Contrary to previous Danish analyses, we found a significant calendar time variation with steadily increasing age-specific incidences from the beginning of $1950 \mathrm{~s}$ until an apparent maximum in mid-1970s.

Key words: Epidemiology, early onset diabetes mellitus, incidence, secular trend, seasonality, geographical distribution, symptom duration.
To obtain new and more detailed information on the epidemiological and public health aspects of diabetes mellitus, we undertook two population-based studies as presented earlier [1, 2]. This report describes the clinical and epidemiological characteristics of diabetes from a series of Danish male birth cohorts, observed during the first 20 years of life [1].

\section{Materials and Methods}

\section{Ascertainment and Verification of Cases}

From the files of the Danish National Conscript Registry all males were identified who were (1) born in Denmark between 1 January 1949 and 31 December 1956, and (2) rejected by the Conscript Registry Board with diabetes or possible diabetes notified as a cause of rejection [1]. This was supplemented with a search in the computerized National Registry of deaths for anyone from these birth cohorts for whom diabetes was mentioned as a cause of death [1]. For all cases hospital records, whenever possible referring to the first admission with diabetes, were traced and scrutinized to verify and establish the time of diagnosis of diabetes; in three cases this information was obtained from general practitioners only. The only diagnostic criterion used was that diabetes should be diagnosed by a doctor; the time of diagnosis, and correspondingly the age at onset, referred to the time when the diagnosis was established in this way. Only cases with age at onset before 20 years were included. From hospital records information was obtained on the duration of symptoms before diagnosis as well as data on hospitalization at onset and - whenever possible - on treatment and conditions to which diabetes might be secondary.

The final material comprised 748 cases, traced in the Conscript Registry, supplemented with 21 cases from death certificates, in total 769 cases. We have estimated that the degree of ascertainment is approximately $95 \%$ [1].

\section{Population Data}

Data on the number of live-born males from the cohorts under study were obtained from Danmarks Statistik [3, 4]. From vital statistics published annually, it was possible to assess the number of deaths and emigrations at each one year age level in the study population, providing estimates of the number of person-years at risk of diabetes for various age and calendar time intervals.

\section{Statistical Analysis}

Intensities (incidence rates) of the diagnosis of diabetes, $\lambda_{\mathrm{a}, \mathrm{c}}$, specified for age intervals (a) and calendar time periods (c), were estimated by the maximum likelihood method by $\mathrm{m}_{\mathrm{a}, \mathrm{c}} / \mathrm{S}_{\mathrm{a}, \mathrm{c}}$ [5]. Here $\mathrm{m}_{\mathrm{a}, \mathrm{c}}$ is the number of new cases in the interval $(a, c)$ and $S_{a, c}$, the corresponding number of person-years at risk, was estimated from the population data as described in [6] after subtraction of the contributions from individuals who emigrated before the age of 20 years. This was done because such persons, if diabetic, would be missed [1]. It has been demonstrated (Andersen and Green, unpublished data) that this procedure ensures 
Table 1. Cases of diabetes mellitus diagnosed before age 20 years amongst Danish male birth cohorts 1949-1956 inclusive: distribution on seasonality of time at diagnosis and duration of symptoms before diagnosis

\begin{tabular}{|c|c|c|c|c|c|c|}
\hline $\begin{array}{l}\text { Duration of symptoms } \\
\text { before diagnosis }\end{array}$ & \multicolumn{6}{|c|}{ Seasonality of diagnosis } \\
\hline$\geqslant 2$ months & 45 & 32 & 37 & 35 & 1 & 150 \\
\hline No symptoms ${ }^{\mathrm{a}}$ & 7 & 5 & 4 & 7 & 0 & 23 \\
\hline Not specified & 2 & 2 & 2 & 4 & 11 & 21 \\
\hline Total & 202 & 188 & 160 & 207 & 12 & 769 \\
\hline
\end{tabular}

a Observation of glycosuria in relation to, for example, routine examinations

Table 2. Cases of diabetes mellitus diagnosed before age 20 years amongst Danish male birth cohorts 1949-1956 inclusive, distributed according to address within regions of Denmark at birth and at time of diagnosis

\begin{tabular}{|c|c|c|c|c|c|}
\hline \multirow{2}{*}{$\begin{array}{l}\text { Address at time of } \\
\text { diagnosis }\end{array}$} & \multicolumn{5}{|c|}{ Address at birth } \\
\hline & Jylland & Fyn & $\begin{array}{l}\text { Greater } \\
\text { Copen- } \\
\text { hagen }\end{array}$ & $\begin{array}{l}\text { Rest of } \\
\text { Den- } \\
\text { mark }\end{array}$ & Total \\
\hline Jylland (Jutland) & 329 & 4 & 10 & 5 & 348 \\
\hline Fyn (Funen) & 7 & 74 & 1 & 4 & 86 \\
\hline Greater Copenhagen & 10 & 3 & 164 & 12 & 189 \\
\hline Rest of Denmark & 7 & 1 & 19 & 116 & 143 \\
\hline $\begin{array}{l}\text { Outside Denmark } \\
\text { (temporarily) }\end{array}$ & 1 & 0 & 2 & 0 & 3 \\
\hline Total & 354 & 82 & 196 & 137 & 769 \\
\hline$\%$ of total & 46.0 & 10.7 & 25.5 & 17.8 & 100.0 \\
\hline $\begin{array}{l}\text { Percentage distribution } \\
\text { of live-born males from } \\
\text { the cohorts 1949-1956, } \\
\text { inclusive }^{\mathrm{a}}\end{array}$ & 48.1 & 9.1 & 25.1 & 17.7 & 100.0 \\
\hline
\end{tabular}

a According to vital statistics $[3,4]$

consistent estimation even if the ratio between the death rate of diabetics and that for non-diabetics is 10 .

The effects of age and calendar time on the intensities were analysed in a log-linear model followed by reduction to a model with quadratic or linear regression on the calendar time in order to further evaluate the calendar time effect. Finally, seasonality of the diagnosis was entered in the log-linear model.

\section{Results}

\section{Clinical Characteristics}

In three of the 769 patients $(0.4 \%)$, diabetes was probably secondary to steroids, pancreatic aplasia and pancreatitis, respectively. In three other cases $(0.4 \%)$ another disease or condition may have been associated with the development of diabetes (drug addiction, extreme obesity and chronic glomerulonephritis, respectively). In the rest (99.2\%), no predisposing conditions were indicated, and these cases were considered idiopathic.

After consulting the hospital records of the idiopathic cases, it was found that insulin therapy was not instituted in one patient, and in ten other cases insulin therapy was started $>1$ year after diagnosis (in nine patients it became permanent therapy within 6 years from diagnosis, and in one patient remained intermittent). In the remainder of patients $(98.6 \%)$, insulin therapy was started within 1 year of diagnosis and continued from then.

Only 10 patients $(1.3 \%)$ were not admitted to hospital at diagnosis, and seven $(0.9 \%$, all hospitalized) died in coma at the time of diagnosis.

A survey of the cases distributed by seasonality of time at diagnosis and duration of symptoms is given in Table 1 . Of the 748 cases with positive information on duration of symptoms, 23 (3.1\%) had diagnosis established at a routine medical examination without preceding symptoms, and $575(76.9 \%)$ had symptoms for $<2$ months before diagnosis. The rest $(20 \%)$ had symptoms for $\geqslant 2$ months.

Among the 757 cases with information on the exact time at diagnosis, there was an excess of cases diagnosed during the autumn and winter months $\left(\chi_{3}^{2}=7.05\right.$, $p=0.07$ ).

\section{Geographical Distribution}

Table 2 shows the geographical distribution of patients in various regions of Denmark with reference to the time of birth as well as of diagnosis. The relative distribution at birth is in close agreement with the corresponding distribution of the total birth cohorts under study. Furthermore, 683 of the patients $(88.8 \%)$ developed the disease in the region in which they were born.

\section{Epidemiological Analysis}

Table 3 shows the patients, with reference to age at diagnosis, in each of the birth cohorts under study; the number of cases from the 1949-cohort is significantly smaller than the rest of the cohorts which are very similar [1]. The cohorts are combined, and the age-specific cumulative incidence rates (defined as the cumulative number of cases divided by the number at risk at birth) are given. Thus, the cumulative incidence rate for the age interval $0-19$ years inclusive shows that $0.24 \%$ of a Danish male birth cohort develop diabetes before reaching the age of 20 years; this figure also gives a rea- 
Table 3. Cases of diabetes mellitus diagnosed before age 20 years amongst Danish male birth cohorts 1949-1956 inclusive, distributed on year of birth and age at diagnosis

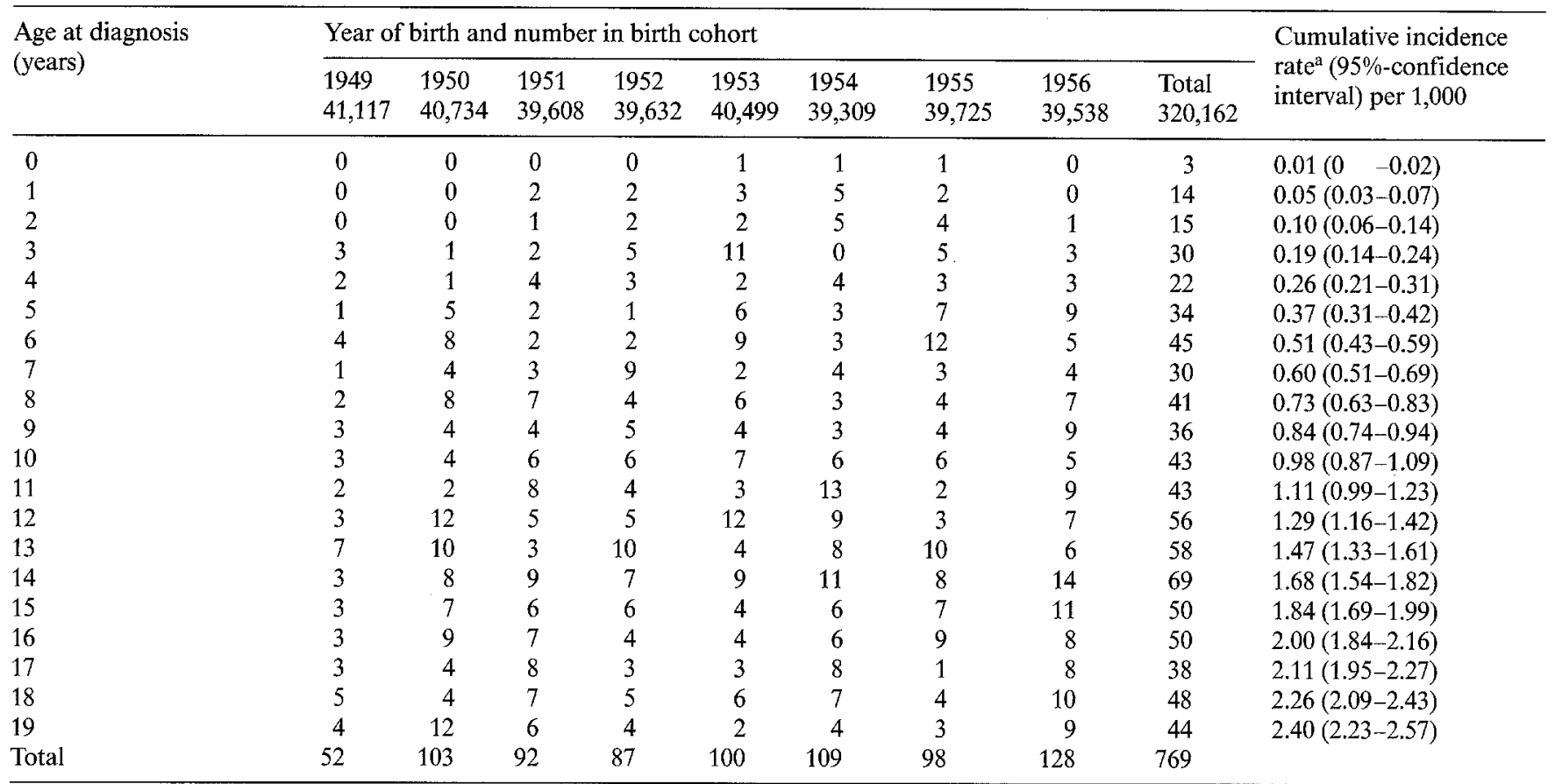

a The cumulative incidence rate is the cumulative number of cases divided by the number at risk at birth

Table 4. The effects of age (a) and calendar time (c) ${ }^{\mathrm{a}}$ on diabetes intensities $\left(\lambda_{a c}\right.$ per $10^{5}$ year) analysed in a regression model. Specification of model: In $\lambda_{\mathrm{a}, \mathrm{c}}=\alpha_{\mathrm{a}}+\gamma+\delta\left(\mathrm{t}_{\mathrm{c}}-\overline{\mathrm{t}}\right)+\eta\left(\mathrm{t}_{\mathrm{c}}-\overline{\mathrm{t}}\right)^{2}$

\begin{tabular}{lc}
\hline Variable & Estimate (standard error) \\
\hline$\alpha_{0-3}$ & $0.171(0.25)^{\mathrm{b}}$ \\
$\alpha_{4-7}$ & $0.422(0.19)^{\mathrm{b}}$ \\
$\alpha_{8-11}$ & $0.310(0.15)^{\mathrm{b}}$ \\
$\alpha_{12-15}$ & $0.417(0.12)^{\mathrm{b}}$ \\
$\alpha_{16-19}$ & set to zero \\
$\gamma$ & $-9.123(0.14)$ \\
$\delta$ & $0.305(0.058)$ \\
$\eta$ & $-0.045(0.022)$ \\
\hline
\end{tabular}

${ }^{\mathrm{a}} \mathbf{t}_{\mathrm{c}}=(1, \ldots . ., 7)$ corresponding to $(1949-1952, \ldots ., 1973-1976) ; \overline{\mathbf{t}}=\mathbf{t}_{4}$, corresponding to $1961-1964 ;{ }^{b}$ standard errors of differences between $\hat{\alpha}_{16-19}$ and the respective $\hat{\alpha}$-value

sonable estimate of the risk of diabetes during this age interval [7]. Assuming that the excess mortality amongst diabetic patients is small in the first decades of life, the cumulative incidence rate at a given age corresponds to the prevalence rate at this age level. Accordingly, from Table 3 an estimate of the male prevalence of diabetes at age 10 and at age 20 years is $0.10 \%$ and $0.24 \%$, respectively. The traditional incidence rates may also be calculated, based on the estimated number of person-years at risk observed in various age intervals. For the birth cohorts combined estimates of incidence rates (per 100,000 individuals/year) for the age intervals $0-4,5-9$, $10-14$ and 15-19 years are 5.9, 13.1, 19.0 and 16.3.
(These figures are given for comparison with other studies, but are not directly comparable with figures based on the regression model where the effect of the calendar time is analysed).

After calculation of maximum likelihood estimates of the diabetes intensities, $\lambda_{\mathrm{a}, \mathrm{c}}$; the intensities were analysed in a log-additive model, namely $\ln \lambda_{\mathrm{a}, \mathrm{c}}=\alpha_{\mathrm{a}}+\beta_{\mathrm{c}}$ where $\alpha_{\mathrm{a}}$ is the effect corresponding to age interval a and $\beta_{\mathrm{c}}$ the effect corresponding to calendar time period $\mathrm{c}$; this model was clearly accepted $\left(\chi_{4}^{2}=1.49 ; p=0.83\right)$. The calendar time effect was further evaluated in a reduced regression model as specified in Table 4; this model was also accepted $\left(\chi_{4}^{2}=4.43 ; p=0.35\right)$. The age effects as well as both of the terms describing the calendar time effect were significant, and the model cannot be further reduced. From these estimates it appears that the calendar time effect increased from 1949 to 1952 to reach a maximum in 1973-1976.

Table 5 shows the diabetes intensities estimated on the basis of the regression model. For those age and calendar time intervals not studied predicted values are indicated with asterisks. For those intervals observed, the estimates from the regression model were generally very similar to the initial maximum likelihood estimates (shown in parentheses).

Finally, seasonality of time at diagnosis was entered together with age and calendar time in a log-additive model, but the effects of the seasons were insignificant $\left(\chi_{3}^{2}=6.28 ; p=0.10\right)$, thus confirming the initial rough analysis (Table 2) without consideration of age and calendar time. 
Table 5. Diabetes intensities per $10^{5}$ year, specified for age intervals and calendar time-periods estimated from regression analysis (see Table 4)

\begin{tabular}{|c|c|c|c|c|c|}
\hline Calendar time period & \multicolumn{5}{|c|}{ Age interval (years) } \\
\hline 1949-1952 & $3.34(1.11)$ & $4.30^{\mathrm{a}}$ & & & \\
\hline $1957-1960$ & $8.85(8.22)$ & $11.37(10.89)$ & $10.16(11.68)$ & $11.32^{\mathrm{a}}$ & \\
\hline $1961-1964$ & $12.57^{\mathrm{a}}$ & $16.15(16.88)$ & $14.44(13.38)$ & $16.07(16.18)$ & $10.59^{\mathrm{a}}$ \\
\hline $1965-1968$ & $16.30^{\mathrm{a}}$ & $20.95^{\mathrm{a}}$ & $18.73(19.09)$ & $20.84(20.82)$ & $13.73(13.80)$ \\
\hline $1979-1980$ & & & & $26.49^{\mathrm{a}}$ & $17.36^{\mathrm{a}}$ \\
\hline
\end{tabular}

In parentheses: initial maximum likelihood estimates; ${ }^{a}$ predicted values according to regression model

\section{Discussion}

It has been established previously that the present material comprises a virtually complete, nation-wide sample of male diabetic patients within the limits defined by the inclusion criteria [1].

The small number of secondary diabetes cases indicates that early onset diabetes is almost completely of the primary (idiopathic) type, and based on the clinical characteristics presented here it is likely that most cases represent Type 1 diabetes; the duration of symptoms before diagnosis is $<2$ months in $75 \%$ of the cases. However, the existence of cases, though few in number, with long periods without insulin treatment indicates that a proportion (probably small) represent other types of diabetes; because of the small number of such cases we have based our analysis on all subjects.

Unfortunately, alterations in the administrative division of Denmark in the early 1970s, followed by changes in the compilation and reporting of vital statistics, restricted our analysis of the geographical variation. With this reservation, our findings confirm the results from another recent Danish incidence-survey of Type 1 diabetes, covering almost 50\% of Denmark [8], that no major geographical variation within Denmark exists. However, there may be differences within the main Danish regions, e.g. between rural and urbanized districts, but it is noteworthy that the number of cases from Greater Copenhagen with the highest population density in Denmark corresponded very well with the number from the rest of Denmark when corrected for the size of the background population (Table 2).

Several studies have reported a relatively increased incidence of Type 1 diabetes during the autumn and winter periods [ 9 review], which others have not been able to confirm [10]. We also found an excess of cases at these times, although not statistically significant, even after adjustment for age and calendar time effects on incidence in the regression model.

Some authors have attempted to explain seasonal variation by delay in diagnosis and admission, in particular for cases in which symptoms of diabetes start in the summer holiday periods. Such a delay would imply that among cases diagnosed in the summer months there should be a relatively higher proportion of patients with acute onset (and therefore short duration of symptoms), and a relatively high proportion of cases, diagnosed in autumn and winter months, with longer duration. Such a systematical trend was not observed in the present study (Table 1). In fact, for the summer months which showed the smallest number of diagnoses, we found relatively fewer cases with short duration of symptoms, while the opposite was found for cases diagnosed during the autumn months. More detailed examination of the possible seasonality requires that all events and symptoms which lead to the final diagnosis be included as variables in the analysis.

One important result from the present study is the demonstration of a significant increase in incidence with increasing calendar time; according to the most parsimonious regression model defining this trend the calendar time effect reached an apparent maximum in the beginning of the 1970 s. Some other studies have reported similar findings while others have not [9 review]. Thus, Christau et al. [8] were unable to demonstrate a calendar time effect in their Danish study from 1970-1975 (in some regions: 1970-1977). With reference to a study from 1925 [11], Christau et al. found no evidence for an increasing incidence in Denmark during the last 50 years. However, studies which have failed to demonstrate a secular trend, have all been performed recently and covered a relatively short registration period; for instance, Christau et al.'s Danish study [8] refers to a period during which the incidence rates remained rather stable according to the predictions from our model (Table 4). Furthermore, a detailed examination of the old study of Heiberg and Heiberg [11] reveals that the Danish incidence of Type 1 diabetes in 1924 was probably several times less than the present level; the discrepancy arises because Christau et al. in their reanalysis of the old figures took the original estimates of the number of Type 1 diabetes (Table 2 in [11]) as representing incident cases, whereas the numbers are actually estimates of prevalent cases; that is, they are several times higher than the number of incident cases. In summary, there seems to be no substantial evidence against a secular increase in Type 1 diabetes in Denmark.

The present study does not explain the secular 
trend. It seems unrealistic to explain it by increasing population frequency of disease-favouring genetic factors due to increasing fertility among diabetic patients, but a more accurate discussion of this possibility must wait for the clarification of the genetic background of Type 1 diabetes [12] as well as reliable data on the fertility of diabetic subjects. We also feel that the secular increase cannot be explained by under-reporting of cases from the initial part of our registration period since the trend remained significant even after exclusion of the 1949 birth cohort with its small number of cases.

Further epidemiological studies will hopefully elucidate and validate the secular increase; such studies might, for example, be based on the inclusion of earlier and later adjacent birth cohorts, and this would also provide an opportunity for the elucidation of the small number of cases from the 1949 cohort. Determinants of the secular increase might be investigated by a comparison of characteristics of cases with diagnosis in different calendar time periods; this approach however, requires that forthcoming intensive immunological, clinical and genetic studies will identify aetiological factors which can be examined in a retrospective (historical) study design.

Acknowledgements. The study was supported financially by a grant (no. 12-1035) to AG from the Danish Medical Research Council.

\section{References}

1. Green A, Hauge M, Holm NV, Rasch LL (1980) Epidemiological studies of diabetes mellitus in Denmark. I. A case finding method based on the National Service Conscript Registry. Diabetologia 19: $355-358$
2. Green A, Hauge M, Holm NV, Rasch LL (1981) Epidemiological studies of diabetes mellitus in Denmark. II. A prevalence study based on insulin prescriptions. Diabetologia 20: 468-470

3. Danmarks Statistik (1962) Statistisk Tabelværk 1962: I ("Agteskaber, fødte og døde 1941-1955"). Copenhagen

4. Danmarks Statistik (1973) Statistisk Tabelværk 1973: XI ("Egteskaber, fødte og døde 1956-1969"). Copenhagen

5. Hoem JM (1976) The statistical theory of demographic rates (with discussion). Scand J Statist 3:169-185

6. Hoem JM (1969) Fertility rates and reproduction rates in a probabilistic setting. Biométrie - Praximétrie 10:38-66

7. Green A (1982) The epidemiologic approach to studies of association betwen HLA and disease. I. The basic measures, concepts and estimation procedures. Tissue Antigens 19: 245-258

8. Christau B, Kromann H, Christy M, Andersen OO, Nerup J (1979) Incidence of insulin-dependent diabetes mellitus $(0-29$ years at onset) in Denmark. Acta Med Scand (Suppl) 624: 54-60

9. Gamble DR (1980) The epidemiology of insulin dependent diabetes, with particular reference to the relationship of virus infection to its etiology. Epidemiol Rev 2: 49 70

10. Crossley JR, Upsdell M (1980) The incidence of juvenile diabetes mellitus in New Zealand. Diabetologia 18:29-34

11. Heiberg KA, Heiberg P (1925) Die Zahl der Krankheitsfälle an Diabetes Mellitus in Dänemark im Jahre 1924. Acta Med Scand 62: $126-130$

12. Green A, Morton NE, Iselius L, Svejgaard A, Platz P, Ryder LP, Hauge M (1982) Genetic studies of insulin-dependent diabetes mellitus: Segregation and linkage analyses. Tissue Antigens 19: 213-221

Received: 27 September 1982

and in revised form: 27 June 1983

Dr. A. Green

University Institute of Clinical Genetics

J.B. Winsløwsvej 17

DK-5000 Odense C

Denmark 